\title{
Two 18-membered epothilones from Sorangium cellulosum So0157-2
}

\author{
Chunhua $\mathrm{Lu}^{1,4}$, Xinli $\mathrm{Liu}^{2,4}$, Yuezhong $\mathrm{Li}^{3}$ and Yuemao Shen ${ }^{1,3}$
}

The Journal of Antibiotics (2010) 63, 571-574; doi:10.1038/ja.2010.81; published online 7 July 2010

Keywords: epothilone; 18-membered macrolides; Sorangium cellulosum So0157-2

Epothilones are 16-membered ring macrolides originally isolated from the bacterium Sorangium cellulosum Soce90, ${ }^{1,2}$ which were found to kill dividing cells by stabilizing microtubules. ${ }^{3}$ Previously, epothiloneproducing strains of the genus Sorangium were isolated and screened in our laboratories. We found that one strain, designated S. cellulosum So0157-2, was able to produce epothilones. ${ }^{4}$ The production of epothilones A and B by S. cellulosum So0157-2 was optimized to industrial scales. ${ }^{5}$ Recently, five new epothilone glycoside derivatives were isolated from this strain. ${ }^{6}$ As a part of our ongoing search for new epothilones from S. cellulosum So0157-2, we focused on the minor and polar components of this strain produced in large-scale fermentations.

The strain S. cellulosum So0157-2 was cultivated in 701 of M26 medium. ${ }^{7}$ Epohtilones $A_{9}$ (3) (3.0 mg), A (4) (90 mg), B (250 mg) and C $(20 \mathrm{mg})$ were isolated from the 701 fermentation extract by repeated column chromatography (Sephadex LH-20, RP-18 and silica gel, Sephadex, Uppsala, Sweden). The polar epothilone-containing fractions were separated by HPLC (Agilent 1200 instrument, Agilent, Palo Alto, CA, USA; $\mathrm{C}_{18}$ column: Zorbax SB-C18, Agilent, $4.6 \times 250 \mathrm{~mm}$, $5 \mu \mathrm{m}$ ), eluting with $65 \%$ methanol at a flow rate of $1.0 \mathrm{ml} \mathrm{min}^{-1}$ to yield compound 1 ( $t_{R} 7.8 \mathrm{~min}, 2.0 \mathrm{mg}$ ) and $2\left(t_{R} 10.9 \mathrm{~min}, 0.8 \mathrm{mg}\right)$. Their structures were established as epothilone-type 18-membered ring macrolides, named epothilones $\mathrm{M}(\mathbf{1})$ and $\mathrm{N}(\mathbf{2})$. In this study, we describe structure elucidation and cytotoxic activity of these two new epothilones.

Compound 1 was isolated as a white powder. The molecular formula was determined to be $\mathrm{C}_{26} \mathrm{H}_{39} \mathrm{NO}_{7} \mathrm{~S}$ by $\mathrm{HR}$ quadrupole time-of-flight $\mathrm{MS}\left(\mathrm{m} / \mathrm{z} 510.2528[\mathrm{M}+\mathrm{H}]^{+}, \quad 532.2344[\mathrm{M}+\mathrm{Na}]^{+}\right.$; calcd. 509.2447) and NMR data (Table 1). The ${ }^{13} \mathrm{C}$ NMR spectrum of 1 displayed 26 carbon signals for five methyl, six methylene, nine methine and six quaternary carbon atoms, including a carbonyl carbon at $\delta 171.9(\mathrm{C}-1)$, together with the ${ }^{1} \mathrm{H}$ NMR spectrum clearly revealed a typical epothilone structure, including the presence of a thiazole ring, a carbon-carbon double bond, an epoxy function and a carboxyl carbonyl group (Table 1). However, compared with epothilone A (4), ${ }^{1,2} \mathbf{1}$ had one less methyl and one more oxymethylene group as a substitutent at the carbon-carbon double bond. Among the various epothilone derivatives, the only known oxymethylenesubstituted compounds are represented by epothilones $\mathrm{A}_{9}$ and $\mathrm{C}_{9}{ }^{8}$ Indeed, the structure of epothilone $\mathrm{A}_{9}$ could explain the ${ }^{13} \mathrm{C} \mathrm{NMR}$ spectrum of 1 . However, the ${ }^{1} \mathrm{H}$ NMR chemical shifts of the oxymethylene protons $(\mathrm{H}-17)$ were observed at $\delta 5.07$ and 5.45 in $\mathbf{1}$, but at $\delta 4.11$ and 4.49 in epothilone $\mathrm{A}_{9}{ }^{8}$ respectively. This difference could be the effect of esterification, indicating that the hydroxymethyl hydroxyl group (17-OH) of epothilone $A_{9}$ could be esterified in $\mathbf{1}$. Moreover, in our work, epothilone $A_{9}$ (3) was isolated too. The unambiguous NMR data assignments for $\mathbf{3}$ provided further support for this esterification (Table 1). The heteronuclear multiple-bond correlations from the oxymethylene protons (H-17) at $\delta 5.07$ and 5.45 to the carbonyl group at $\delta 171.9(\mathrm{C}-1)$ indicated the presence of an ester bond between this oxymethylene and the carboxyl group. Therefore, compound 1 was determined to be an 18-membered epothilone-type macrolide, designated as epothilone $\mathrm{M}$.

The relative structure of $\mathbf{1}$ was assumed to be the same as other epothilones. However, the analysis of NOESY correlations revealed that 1 must have two different conformations ( $\mathbf{1 a}$ and $\mathbf{1 b}$, Figure 1) in $\mathrm{CDCl}_{3}$ at room temperature, because otherwise the vinyl proton $(\delta 6.69, \mathrm{H}-18)$ could not simultaneously have NOE correlations with $\mathrm{H}_{2}-14$ and $\mathrm{H}-15$. Moreover, the observation of an NOE correlation between H-3 and H-6 in 1 was intriguing, which was observed in 3 and 4 as well. This indicates a twist of the epothilone 16-membered macrolide ring (3, $\mathbf{4 a}$ and $\mathbf{4 b}$, Figure 1), which is consistent with that

\footnotetext{
${ }^{1}$ Key Laboratory of the Ministry of Education for Cell Biology and Tumor Cell Engineering, Xiamen Engineering Research Center of Marine Microbial Drug Discovery, Fujian Laboratory of Pharmaceutical Engineering; School of Life Sciences, Xiamen University, Fujian, PR China; ${ }^{2}$ Shandong Provincial Key Laboratory of Microbial Engineering, Shandong Institute of Light Industry, Shandong, PR China and ${ }^{3}$ State Key Laboratory of Microbial Technology, School of Life Sciences, Shandong University, Shandong, PR China ${ }^{4}$ These authors contributed equally to this work.

Correspondence: Professor Y Li, School of Life Sciences, Shandong University, Jinan, Shandong 250100, PR China.

E-mail: lilab@sdu.edu.cn or Professor Dr Y Shen, School of Life Sciences, Xiamen University, 422 South Siming Road, Xiamen, Fujian 361005, PR China.

E-mail: yshen@xmu.edu.cn
}

Received 28 January 2010; revised 20 April 2010; accepted 21 April 2010; published online 7 July 2010 
Table 1 The NMR data for compounds 1, 2 and 3 (in $\mathrm{CDCl}_{3}, \delta$ in p.p.m., $J$ in $\mathrm{Hz}$ )

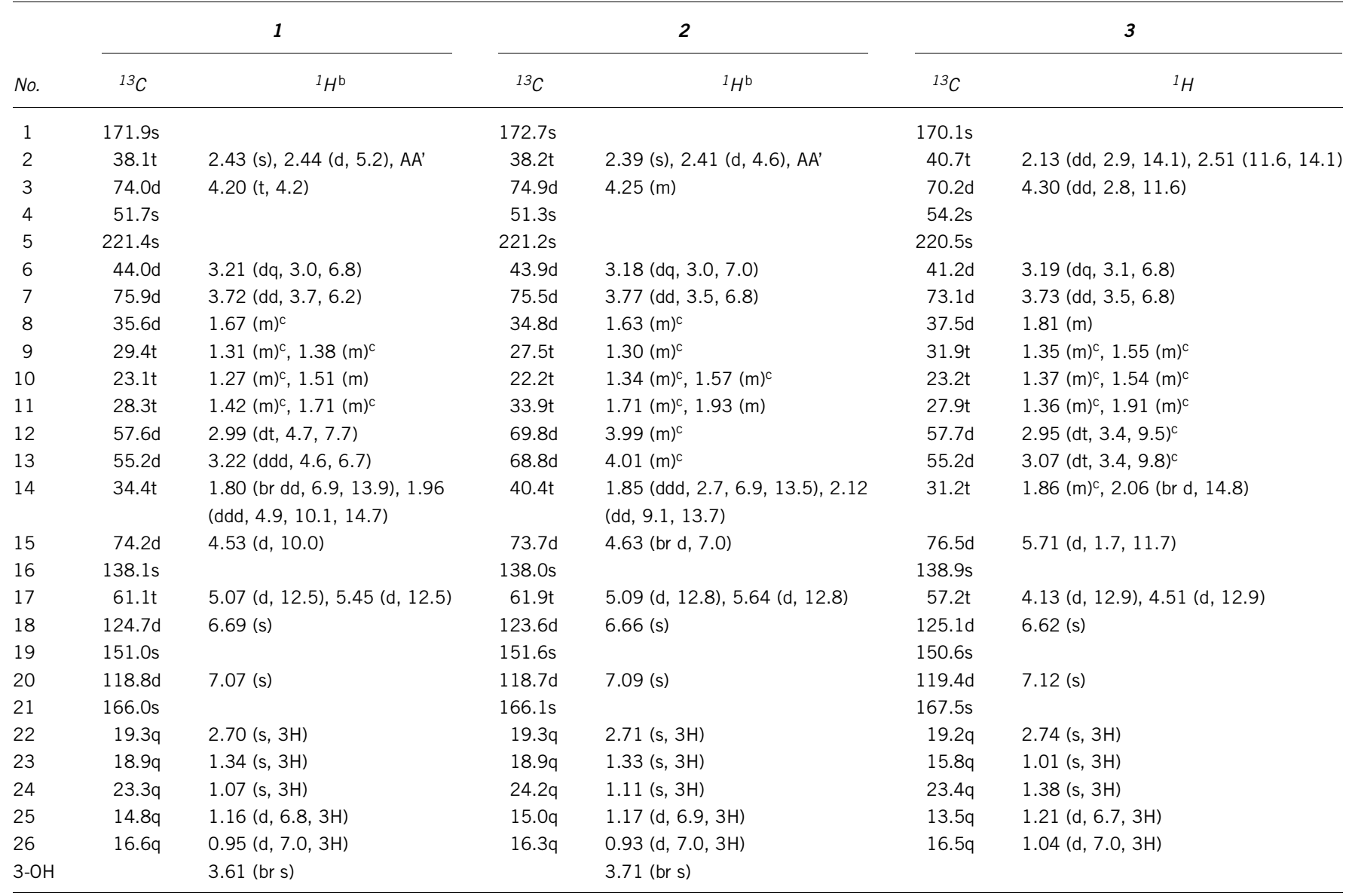

${ }^{a} 1 \mathrm{D}$ - and 2D-NMR spectra were recorded in $\mathrm{CDCl}_{3}$ on a Bruker DRX-600 instrument (Bruker, Fällanden, Switzerland).

bProton signal is integrated to $1 \mathrm{H}$ except for the otherwise indicated.

cSignals overlapped.

of epothilone A in binding to tubulin. ${ }^{9,10}$ However, in both $\mathbf{3}$ and $\mathbf{4}$, the macrolide ring has only one preferred conformation. But NOESY experiment indicated the rotation of the side chain at C-17 in 4 but not in 3 (Figure 1). ${ }^{1}$

Compound 2 was obtained as a white powder. The molecular formula $\mathrm{C}_{26} \mathrm{H}_{40} \mathrm{ClNO}_{7} \mathrm{~S}$ determined by the $\mathrm{HR}$ quadrupole timeof-flight MS data $\left(\mathrm{m} / \mathrm{z} 546.2295[\mathrm{M}+\mathrm{H}]^{+}, 568.2065[\mathrm{M}+\mathrm{Na}]^{+}\right.$; calcd. 545.2214), together with the NMR data (Table 1), indicated that $\mathbf{2}$ had nearly identical structural features as those found in $\mathbf{1}$, except that the C-12/C-13 epoxy function in $\mathbf{1}$ was opened in 2 . The HR MS data showed isotopic quasi-molecular peak triplets at $\mathrm{m} / \mathrm{z}$ $546 / 547 / 548$ and 568/569/570, with the ratio of $[\mathrm{M}] /[\mathrm{M}+2]$ being equal to 3:1 (Supplementary Information), indicating that opening of the epoxy ring in $\mathbf{2}$ is due to chlorine-substitution. This conclusion was supported by the ${ }^{13} \mathrm{C}$ NMR downfield shifts from $\delta 55.2(\mathrm{C}-12)$ and 57.7 (C-13) in 1 to $\delta 69.8$ (C-12) and 68.8 (C-13) in 2 (Table 1), and NMR data comparison with trans-12,13-hydroxylated epothilone A and cis-12,13-hydroxylated epothilone A. ${ }^{11}$ Unambiguous NMR assignments were made on the basis of heteronuclear multiple-bond correlation, heteronuclear single-quantum coherence and ${ }^{1} \mathrm{H}-{ }^{1} \mathrm{H}$ COSY experiments. Thus, the structure of $\mathbf{2}$ was established to be 12,13-deepoxy-12-chloro-13-hydroxyl epothilone $\mathrm{M}$, designated as epothilone N. The relative configurations of C-12 and C-13 in 2 were determined by NOESY experiment. The NOEs between $\mathrm{H}-15$ and
$\mathrm{H}-14 \alpha(\delta$ 1.85), and $\mathrm{H}-14 \beta(\delta$ 2.12) and $\mathrm{H}-13(\delta$ 4.01) indicated the $\alpha$-orientation of $13-\mathrm{OH}$ (Figure 1 ). The relative configuration of $12-\mathrm{Cl}$ was assumed to be $\beta$, because the opening of the $\mathrm{C}-12 / \mathrm{C}-13$ epoxy ring by chlorination would presumably proceed by an $\mathrm{S}_{\mathrm{N}} 2$ mechanism.

The cytotoxic activity of epothilones $M(1), N(2)$ and $A_{9}(3)$ against the MDA-MB-435 cell line was assayed by the MTT method. ${ }^{12}$ Compounds 1 and 3 showed similar activities with $\mathrm{IC}_{50}$ of 0.12 and $0.26 \mu \mathrm{M}$, respectively, which is consistent with the values reported for epothilone $\mathrm{A}_{9}$ against the mouse fibroblast cell line $\mathrm{L} 929$ ( $\mathrm{IC}_{50}$ $0.20 \mu \mathrm{M}){ }^{8}$ In contrast, compound 2 , an epoxide-opened derivative, showed only modest activity with an $\mathrm{IC}_{50}$ of $2.47 \mu \mathrm{M}$, which is similar to the C-12/C-13 diol derivatives of epothilones A and B. ${ }^{11,13}$

Epothilones A and B were first isolated from S. cellulosum Soce 90 in 1993. ${ }^{1,2}$ The search for new epothilone derivatives, spurred by their potent antitumor activity, resulted in the isolation and identification of dozens of natural epothilone-type 16-membered macrolides. ${ }^{8,14,15}$ The structural variations of natural epothilone-type macrolides are mainly due to the presence of a C-12/C-13 epoxide ring or a corresponding carbon-carbon double bond, and the different methyl substitutions and dehydrogenations in the macrolide ring. Variations of the thiazole side chain at $\mathrm{C}-15$ observed were hydroxylation at the vinyl methyl group in epothilones $\mathrm{A}_{9}$ and $\mathrm{C}_{9}$, and at the thiazole methyl group in epothilones $\mathrm{E}$ and $\mathrm{F}^{8}$ One ethyl thiazole derivative, 


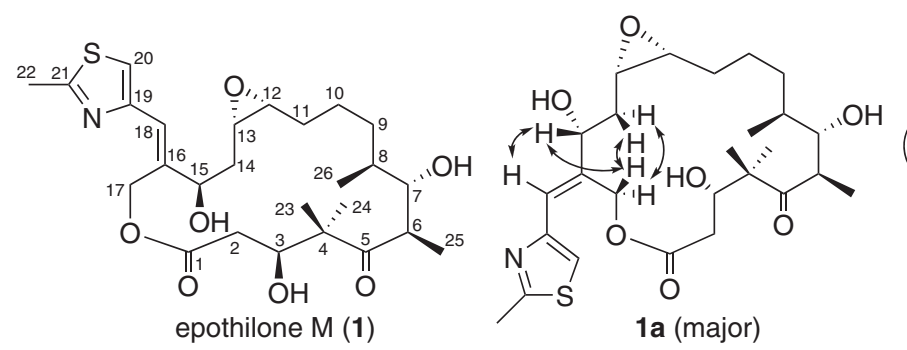

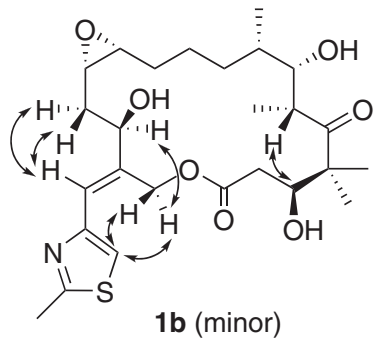

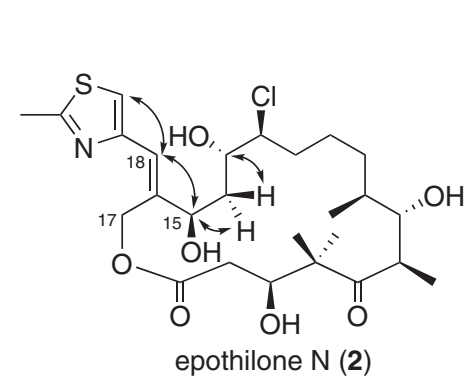

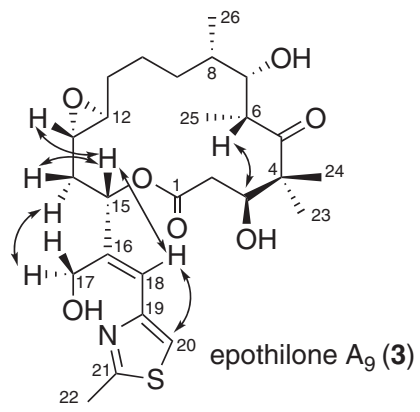<smiles>CO[C@@H](CC1OC1CCC[C@@H]1OC1C[C@@H](C)[C@@H](O)CC(=O)O)/C(C)=C/c1csc(C)n1</smiles>

epothilone A (4)

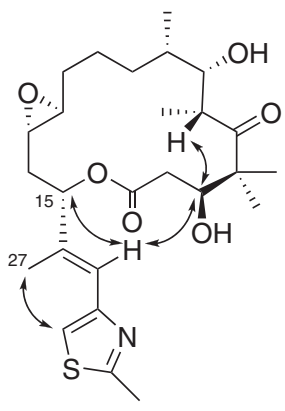

4a (major)

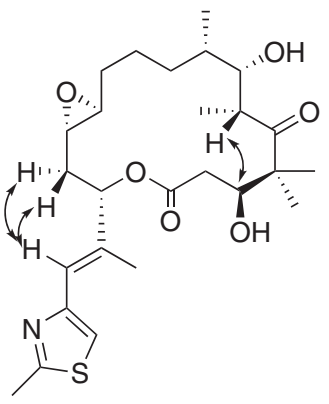

$4 b$ (minor)

Figure 1 Structures of compounds $1,2,3$ and 4 , and the preferred conformations determined by the NOEs as indicated $(H \leftrightarrow H)$.

epothilone $\mathrm{B}_{10}$, was isolated as well. ${ }^{8}$ Most recently, five glycosylated derivatives of epothilones were isolated from S. cellulosum So0157-2, which represented the first example of epothilone glycosides. ${ }^{6}$ However, most epothilones reported previously were 16-membered macrolides, except for epothilones $\mathrm{I}_{1}-\mathrm{I}_{6}$, which are produced by the mutant strain S. cellulosum So ce90/B2. ${ }^{8}$ Those epothilones presumably arise from an extra cycle of chain elongation after the introduction of C-9/C-10.

Epothilones $\mathrm{M}$ and $\mathrm{N}$, isolated from a wild-type strain S. cellulosum So0157-2 in this work, are 18-membered epothilones having the same polyketide chain as the 16-membered analogs. In light of the significant cytotoxic activities of epothilones $\mathrm{M}$ and $\mathrm{N}$ in vitro, it is worth attempting to produce more 18-membered ring derivatives by bioengineering of $S$. cellulosum So0157-2. Although both of the two novel 18-membered epothilones are 10-100 times less potent than epothilones $\mathrm{A}$ and $\mathrm{B}$, it would still be worth testing their in vivo antitumor activity, because some antitumor natural products have been reported to have low activity in in vitro test systems, but a dramatic in vivo antitumor activity. ${ }^{16}$ Overall, our work points to a new direction for generating novel epothilones for antitumor drug discovery.

Epothilone $M(1)$. white powder; $[\alpha]_{\mathrm{D}}^{20}+104.27$ (c 0.12, methanol). IR (KBr): $v_{\max } 3384,2963,2931,1726,1691 \mathrm{~cm}^{-1}$; HR quadrupole time-of-flight MS $m / z: 510.2528[\mathrm{M}+\mathrm{H}]^{+}, 532.2344[\mathrm{M}+\mathrm{Na}]^{+} ;{ }^{1} \mathrm{H}$ and ${ }^{13} \mathrm{C}$ NMR data, see Table 1.
Epothilone $N$ (2). white powder; $[\alpha]_{\mathrm{D}}{ }^{20}+31.0$ ( $c 0.1$, methanol); IR (KBr): $v_{\max } 3440,3471,2958,2924,1725,1722 \mathrm{~cm}^{-1}$; HR quadrupole time-of-flight MS m/z: $546.2295[\mathrm{M}+\mathrm{H}]^{+}, 568.2065[\mathrm{M}+\mathrm{Na}]^{+} ;{ }^{1} \mathrm{H}$ and ${ }^{13} \mathrm{C}$ NMR data, see Table 1.

\section{ACKNOWLEDGEMENTS}

This study was partially supported by the National Natural Science Fund for Distinguished Young Scholars (30325044 to YS, 30825001 to YL), Key Program of International Cooperation, Ministry of Science and Technology of China (2007DFA30970) and the 863 Program of China (20060102Z1083).

1 Höfle, G. et al. Epothilone A and B-novel 16-membered macrolides with cytotoxic activity: isolation, crystal structure, and conformation in solution. Angew. Chem. Intern. Ed. Engl. 35, 1567-1569 (1996).

2 Gerth, K., Bedorf, N., Höfle, G., Irschik, H. \& Reichenbach, H. Epothilons A and B: antifungal and cytotoxic compounds from Sorangium cellulosum (Myxobacteria). Production, physico-chemical and biological properties. J. Antibiot. 49, 560-563 (1996).

3 Bollag, D. M. et al. Epothilones, a new class of microtubule-stabilizing agents with a taxol-like mechanism of action. Cancer Res. 55, 2325-2333 (1995).

$4 \mathrm{Li}, \mathrm{Z}$. F. et al. Evolutionary diversity of ketoacyl synthases in cellulolytic myxobacterium Sorangium. Syst. Appl. Microbiol. 30, 189-1996 (2007).

5 Gong, G. L. et al. Mutation and a high-throughput screening method for improving the production of Epothilones of Sorangium. J. Ind. Microbiol. Biotechnol. 34, 615-623 (2007).

6 Wang, J. et al. Five new epothilone metabolites from Sorangium cellulosum strain So0157-2. J. Antibiot. 62, 483-487 (2009). 
7 Nguimbi, E. et al. 16S-23S ribosomal DNA intergenic spacer regions in cellulolytic myxobacteria and differentiation of closely related strains. Syst. Appl. Microbiol. 26, 262-268 (2003).

8 Hardt, I. H. et al. New natural epothilones from Sorangium cellulosum, strains So ce90/ B2 and So ce90/D13: isolation, structure elucidation, and SAR studies. J. Nat. Prod. 64, 847-856 (2001).

9 Heinz, D. W., Schubert, W. \& Höfle, G. Much anticipated-the bioactive conformation of epothilone and its binding to tubulin. Angew. Chem. Int. Ed. 44, 1298-1301 (2005).

10 Sánchez-Pedregal, V. M. et al. The tubulin-bound conformation of discodermolide derived by NMR studies in solution supports a common pharmacophore model for epothilone and discodermolide13. Angew. Chem. Int. Ed. 45, 7388-7394 (2006).
11 Wang, Y.- L. et al. Microbial transformation of epothilone A by Aspergillus niger AS 3.739. J. Asian Nat. Prod. Res. 11, 357-364 (2009).

12 Mosmann, T. Rapid colorimetric assay for cellular growth and survival: application to proliferation and cytotoxicity assays. J. Immunol. Methods 65, 55-63 (1983).

13 Sefkow, M., Kiffe, M. \& Höfle, G. Derivatization of the C12-C13 functional groups of epothilones A, B and C. Bioorg. Med. Chem. Lett. 8, 3031-3036 (1998).

14 Starks, C. M., Zhou, Y., Liu, F. \& Licari, P. J. Isolation and characterization of new epothilone analogues from recombinant Myxococcus xanthus fermentations. J. Nat. Prod. 66, 1313-1317 (2003).

15 Arslanian, R. L. et al. Large-scale isolation and crystallization of epothilone D from Myxococcus xanthus cultures. J. Nat. Prod. 65, 570-572 (2002).

16 Cassady, J. M., Chan, K. K., Floss, H. G. \& Leistner, E. Recent developments in the maytansinoid antitumor agents. Chem. Pharm. Bull. 52, 1-26 (2004).

Supplementary Information accompanies the paper on The Journal of Antibiotics website (http://www.nature.com/ja) 